\title{
The Self-Chasing Instrument: Idealism, Vision, and Judgement
}

\author{
Ben Woodard
}

While much phenomenology, particularly in its more theological variants, has made various cases for how we can supposedly perceive the imperceivable, or the invisible, this is often done despite, or in direct confrontation with, the claims of the natural sciences. Some inherent human capacity to perceive or sense (often via a transcendental ego or more general account of the given and givenness) is set against the purported limitations and dangers of the scopic or, more generally, of the very function of representation.

In the following I hope to address how vision, or representation generically construed, can benefit from a conjoined idealist skepticism and a naturalist materialisation by way of F.W.J. von Schelling's work. Schelling's Naturphilosophie, rather than being a reductionist naturalism, 
or an idealism about nature, attempts to articulate how we conceive of a nature which philosophises and senses through us. In this regard, the various senses of the human body, the natural capacities for sensation which phenomenology attempts to de-materialise, function as nature attempting to access itself through the production of experiences, cognitions, and representations. Thus, our various complex capacities to abstract and perceive such abstraction are not in spite of nature, or in phenomenological isolation from it, but because of nature's generative complexity.

By creating a feedback loop between naturalism and idealism, Schelling's work generates a very particular form of second-order empiricism in which apparently ideal, or purportedly human capacities for regulating, or normalising our experiences, are part of the same world to which nature belongs. Schelling therefore resists a form of judgement, or law, which is merely the force of the normative removed from sense. In this way, vision and representation become actions in the world that create as much as they discover things supposedly 'above' it. In this regard, the abstract becomes a function whose morphology is difficult, but not impossible, to determine. If thinking is that form of vision which 'sees' thought, then we can investigate idealism as that form of thought which attempts to track and legislate the ways in which thought attempts to see itself, and importantly judge itself, as thought. In the following discussion we will investigate a narrow instance of this, namely, what the normative becomes which naturalism is broadly expanded. 


\section{Idealism and Vision}

As a philosophical tradition, idealism is generally reduced to two related forms, one ontological and the other epistemological. The first strain of idealism is generally taken to mean that what exists, or what is, is mind. Or, slightly more specifically, the general thesis of ontological idealism would be that what exists is mind dependent (i.e., what I think is, or what god thinks is). Various caveats and questions can be raised immediately but, importantly, this is often taken, at least by the numerous critics of idealism, as self-evidentially problematic. The ontological idealist, her enemies assume, believes straightforwardly that reality pours out of the mind of beings (human or otherwise). The second form, the epistemological one, claims that all we can know is mind-dependent, or what we know is always constructed by minds without making deeper claims about substance or the ontological constitution of the world.

Some figures have argued for one form and not the other while Berkeley, at least as it is traditionally stated, argued that you could not adhere to one form without adopting the other. This division of idealism into ontological and epistemological variants covers over several problems and complications which are directly relevant for our investigation here regarding the relationship between vision and judgement (which must necessarily pass through vision). Immediately one can notice that the general outline of the ontological and epistemological strands of idealism says nothing about what mind is using to construct the world; whether we admit there is only 
my mind, or many minds; how is it that minds communicate if there are only minds; and whether many ontological idealists emphatically state that the world is mind or merely is mind-like?

In relation to the latter point, that the world may be mind-like, this can be taken as a claim following scepticism regarding the role and function of substance, or matter, as having an explanatory role. That is, in saying the world is mind-like, many idealist philosophers are simply claiming that things (or objects, or matter) are potentially secondary while processes, flows, dynamisms, et cetera are primary. In this regard, the mind-dependence of the epistemological claim shifts parameters. Mind-dependence does not mean that one claims that the world is constructed entirely out of my, or anyone's, head substance, but that common features of our visible world, or pragmatic world, should not be taken as readymade, but must be taken as being actively coded by our senses which are themselves not giving us direct relations to the world but are instead producing conceptually overloaded entities that we engage as immediate experience.

An immediate wrinkle in the general critique of idealism, particularly in numerous post-structuralist or post-modern thinkers, becomes apparent. Many of these critiques would assert that idealism equates representations with the represented yet, given the deep scepticism in nearly every form of idealism, a scepticism that maintains a difference between mind-like and not mind-like processes, such an idealism would become a direct realism and could no longer be considered an idealism. The crude caricature of ontological idealism would make it 
impossible for either ontological or epistemological idealists to make judgements, even in the most basic sense of things, or processes, being mind-like or minded.

That visual (and all other forms of) phenomena involve our active participation is a philosophical claim most recognised as belonging to Kant, that our faculties build the world out of more rudimentary relations to the world as it is. Traditionally, the general idealist epistemological claim that we actively participate in the construction of the world was taken as one of hubris, when in fact, it was directed against empiricists, as well as objectivists who, in the view of idealism, were attempting to paint an image of experience that was decidedly simple and unproblematic.

In this sense, many idealists (from Berkeley up to Bradley if not after) did not see their form of philosophy as opposed to any kind of realism, but rather to a crude materialism that attempted to dismiss or overly psychologise experience. This is evident in the fact that thinkers such as F.H. Bradley argued that experience was our most direct access (in a realist form) to reality but that, nevertheless, this access was incomplete and required extensive methodological rigor, and the use of sciences such as logic, to widen the ambit of experience in order to better understand the levels of appearance which had long settled on the surface of the world undulating beneath it.

For nothing is actually removed from existence by being labelled 'appearance.' What appears is there, and must be dealt with; but materialism has no rational way of dealing with appearance. Appearance must belong, and yet cannot belong, to the extended. It neither is able to fall somewhere apart, since there 
is no other real place; nor ought it, since, if so, the relation would vanish and appearance would cease to be derivative. But, on the other side, if it belongs in any sense to the reality, how can it be shown not to infect that with its own unreal character? ${ }^{1}$

Another way of complicating the caricature of idealism as merely fabricating the world in total, which is directly relevant to our goal here, is to examine the general relation between idealism and the sciences. Berkeley, who is often taken as the most subjective idealist (even by other idealists) wrote a tract on vision entitled An Essay Towards a New Theory of Vision (1709). While some historical hand-waving has been done to claim that in this initial text Berkeley worked as a scientist while in his later work he functioned as a pure idealist, this lacks any significant proof that I can find. Berkeley begins his text with the idea that while we experience distance we cannot really see distance as such. He follows this up by saying that distance, as an experience, is a judgement that is not given to us by our senses. The great space where we place various objects (apartments, streets, garbage bins) is constructed to orient the space around us which is a judgement our mind makes on our visual experience and not, again in the general idealist tradition, one ready-made.

Berkeley writes:

Now though the Accounts here given of perceiving near Distance by Sight are received for true, and accordingly made use of in determining the apparent Places of Objects, they do nevertheless seem very

${ }^{1}$ F.H. Bradley, Appearance and Reality: A Metaphysical Essay (London: George Allen, 1893), 15. 
unsatisfactory: And that for these following Reasons. It is evident that when the Mind perceives any Idea, not immediately and of itself, it must be by the means of some other Idea: Thus, for Instance, the Passions which are in the Mind of another, are of themselves to me invisible. I may nevertheless perceive them by Sight, though not immediately, yet by means of the Colours they produce in the Countenance. We often see Shame or Fear in the Looks of a Man, by perceiving the Changes of his Countenance to Red or Pale. ${ }^{2}$

Several points need to be clarified. First, as Berkeley makes clear, the word Idea he takes to be as generic as the use of the words Thing or Object, but merely with the added emphasis that our mind is coding, or actively adding to, that which we encounter as an instance of individuated experience. Furthermore, while our experience consists of chaining together these ideas to give us perception, or vision, we are still aware of the fact that certain chains of Ideas point to barriers and boundaries which our vision is attempting to shortcut, whether the notion of how distance relates to clarity or obscurity, or whether the expression on someone's face is indicative of a mental or behavioural state. ${ }^{3}$ One way Berkeley argues we can parse this difference is by marking a difference between tangible magnitude and visual magnitude. ${ }^{4}$ Berkeley believes we need these senses to check, or articulate one another's

${ }^{2}$ George Berkeley, An Essay Towards a New Theory of Vision (London: Classical Reprint, 1709), 13.

${ }^{3}$ We will see below that the very operation of a mind productively chaining together experiences is something the later idealists see as a fatal flaw not only to Berkeley, but to the empiricist tradition as a whole.

${ }^{4}$ Berkeley, Theory of Vision, 15. 
limitations, because while we may scientifically understand optics or geometry, we also know that we add these formulations after the experiences they explain.

Despite the general treatment of idealism as antiscientific, Berkeley is not dismissing science as useless at all, as he would not celebrate numerous treatises on optics or studies of the eye if this were so. Rather, Berkeley thinks there are means of explaining vision internal to the experience of it which have a different (not better, or more advanced) way of explaining our articulation of the senses as part of, but not all of, experience. For Berkeley, if the mind adds something to the visual experience, the mind still relies upon the data that vision provides. An experience of vision would be the constructive capacities of the mind combined with the act of seeing.

For instance, Berkeley says it is absurd to think that we experience multiple objects, or that an object (or Idea) has multiple simultaneous forms. Yet our senses give us very different perceptions of the same object. Berkeley gives the example of a coach passing in the street below one's window. The way I see the distance the coach is moving with my vision, and the way I track it by ear it are different for me, yet both give more or less accurate perceptions that the coach is moving. ${ }^{5}$

Berkeley argues that our tactile experience of the world checks and balances out the visual (or for that matter auditory) depictions of it. For instance, Berkeley argues that someone who had just been given sight would not understand perspective or magnitude across distances

5 Ibid., 13. 
without having moved through the world and interacted with it by grasping, moving, and examining it.

Despite the usual critique and/or dismissal of Berkeley as over-emphasising the visual account taken in the phrase 'to be is to be perceived,' his notion of perception falls closer to that of representation than it does to a particular account of vision, or to even an individual's account of perception. Thus vision, perception, representation and judgement would seem to slide into one another, but Berkeley argues that each sense is a type of perception. Perceptions, when taken together, give the material for experience but this material requires a judgement on our part.

\section{Vision and Representation}

In his Principles of Human Knowledge, Berkeley continues the discussion of perception with being, or existence, as he states that it is unintelligible to say that things could have existence without being in a perceptual relation with some spirit, some active representer (which need not be human). Immediately, it would appear that Berkeley is embodying the worst of his stereotypes: that if all the perceivers of the world disappeared then there would be no world. But we must always take care to keep in mind that this is impossible for Berkeley because of his insistence that the two strains of idealism mentioned above, that of the ontological and the epistemological, must be tied together.

In other words, Berkeley does not think the world would disappear without perceivers but that the notion of world is unintelligible without a notion of representation 
congealing the various senses in the minds of those perceiving. ${ }^{6}$

This fact is further evidenced by the way in which Berkeley insists that natural order, and natural law, exist and are both distinguishable from imaginary things, or conglomerations of sensed things. Nature imprints on us 'real things' of which images or ideas are only copies.' Berkeley then begins listing possible objections to his general theory of the fundamentality of sense, and of the consequences of his immaterialism. To quote at length:

First then, it will be objected that by the foregoing principles, all that is real and substantial in Nature is banished out of the world: and instead thereof a chimerical scheme of ideas takes place. All things that exist, exist only in the mind, that is, they are purely notional. What therefore becomes of the sun, moon, and stars? What must we think of houses, rivers, mountains, trees, stones; nay, even of our own bodies? Are all these but so many chimeras and illusions on the fancy? To all which, and whatever else of the same sort may be objected, I answer, that by the principles premised, we are not deprived of any one thing in Nature. Whatever we see, feel, hear, or anywise conceive or understand, remains as secure as ever, and is as real as ever. There is a rerum natura, and the distinction between realities and chimeras retains its full force. ${ }^{8}$

Thus, while imagined fancies and sensed things exist equally in the mind (and here Berkeley is in general

${ }^{6}$ Berkeley, Principles of Human Knowledge (Oxford: Oxford University Press, 1710/1996) 26-27.

7 Ibid., 37.

8 Ibid., 38. 
agreement with Hume) there is an externally designated, though not necessarily material, order to things, and this order is real. Thus, despite the use of the world essence, Berkeley is not making any strong claims about the ontological or metaphysical claims about the world; to make such claims, again generally following Hume, is simply to add more confusion to human existence, confusion which leads us into sceptical loops and a pervasive sense of unhappiness.

Following this, we could argue that Berkeley's only ontological or metaphysical claims are negative ones: if it is not perceptible it is not useful to speak of it. It remains a debate, then, whether Berkeley carries a strong epistemological idealist position (all we can know are ideas) as well as a weak ontological position (what exist are ideas and minds). The upshot of Berkeley's claim, and one that is common to idealist philosophies in general, is a formalisation of existence that emphasises ontological parsimony. Again, to quote Berkeley:

in this sense, the sun that I see by day is the real sun, and that which I imagine by night is the idea of the former. In the sense here given of reality, it is evident that every vegetable, star, mineral, and in general each part of the mundane system, is as much a real being by our principles as by any other. ${ }^{9}$

The general idea that both reflection and perception merely pick up on a deeper ontological or objective structure in the world is a persistent thread in idealism. Whether Hegel's identity-in-difference, Schelling's Law of

9 Ibid., 39. 
the World (or Weltgesetz where everything is what it is to the extent it is not something else $\left.\mathrm{e}^{10}\right)$, or Bosanquet's reality principle (everything is real so long as you do not take it for more than it is $)^{11}$, the basic ontological claim of the idealist tradition becomes one of pseudo-holistic preservation: that ontological existence is to be distributed, or at least engaged with as distributed, is a problem which seems at odds with the limited and particular view of a thinking person entering, and at least partially constructing, their world.

It is here that representation becomes as necessary as it is problematic. Not only does it become necessary to explain the means by which ideas are copies of what occurs in reality, as well as being tied to reflection (the rational process by which we separate mere chimeras of the mind from ideas as sensed), but it is necessary to explain how is it that representation functions as part of reality, as part of the real. Even if, following Berkeley, we do not want to admit that representation functions on its own, that is, that all abstractions are merely the abuse of words, the extension of a word's function beyond its useful remit, representation presents us with a specific problem. The question is not only how is it that representation functions in relation to the real things, sensed things, and imaginary things (all being equally existent in the mind)

${ }_{10}$ F.W.J. von Schelling, Darstellung der rein-rationalen Philosophie (SW II/1, 492) quoted in Iain Hamilton Grant, 'The Law of Insuperable Environment: What is Exhibited in the Exhibition of the Process of Nature?', Analecta Hermenutica 5, (2013): 3-4, accessed February 19, 2017.

11 Quoted in Iain Hamilton Grant, 'Everything', The Monist 98, no. 3 (2015): 156-167, 156. 
but how does representation, as a part of the world, function as just another thing?

Here we return to the question of how representation functions in relation to perception, to how representation is a rarefied form of perception but also its unifying power. Judgement synthesises experience as we know it by combining sense data and our intuitions. But, and this is particularly evident in objective idealism (Schelling and Peirce), we cannot definitively fix the source of either the origin of sensations, their organisation as perceptions, as well as the ultimate source of our intuitions.

This is not to throw up our hands and abandon any progressive or constructive aim at knowledge, or at better explaining our perceptual capacities, or our normative capacity for judgement, but only suggests that generic or axiomatic claims arise when an ultimate ground is deemed impossible or simply hard to find. The way in which these capacities check and bolster, or ground and unground one another, shifts of course from thinker to thinker. While Kant was rather certain regarding the self-grounding nature of judgement, he was far more cautious regarding the source and location (less so the function) of the imagination or the human capacity to schematise. For Kant, such a capacity resided in the depths of the human soul. ${ }^{12}$

Schelling, as well as many purportedly anti-idealist thinkers who would follow him (such as Helmholtz and Oersted) deepen the effect of sense and the external world on the apparatuses of the self and how this intake

12 Immanuel Kant, Critique of Pure Reason, trans. Norman Kemp Smith (New York: St Martin's Press, 1929), A141/B180-181. 
of sensory data is processed and fed into a less and less internalised capacity for mapping, navigating and judging which action to take. ${ }^{13}$ In Schelling's thought, as well as Peirce's and other objective idealists, this means that idealism is not simply opposed to naturalism, but that any naturalism adequate to its own foundational explanatory claim must allow for minds and thoughts to emerge.

It is in this regard that the closeness of the ontological and epistemological relation of types of idealism must be questioned contra Berkeley. Since, if thought and the logic of the mind emerges from nature this does not, following Schelling for instance, entail that the rules or means of explaining nature's various domains necessarily apply to thought as well. Just as the domains of nature are more or less accurately described according to fields of knowledge (biology, chemistry, physics and so on), so too should the behaviour and function of the mind require a different set of tools and theories (psychology, sociology, mythology etc.).

But beyond merely endorsing the cognitive sciences, Schelling's claim (which of course historically predates cognitive science) is that transcendental philosophy implies a different method, since the object of investigation is also that which is doing the investigation and thus a certain failure is built in to the depth of the examination. This is not because there is something specific about the structure of mind but that, for Schelling, nothing can fully become an object to itself at the level of nature.

13 See Iain Hamilton Grant, Philosophies of Nature after Schelling (London: Continuum International Publishing Group, 2006). 
Furthermore, this is not to simply endorse a defeatist attitude, since Schelling's accompanying claim is that the clues to the mind can be also found in a diagonal manner, in the function and behaviour of non-minded nature.

This in turn complicates the self-regulatory powers of the mind. While Kant is comfortable saying the selfgrounding status of natural cognition proves adequate to explain the reach and power of judgement, Schelling's naturalisation of cognition, as well as his assertion regarding the fundamental limit of self-access, provides a messier picture of what judgement could be.

One avenue worth taking, for our purposes here, is to explain how Schelling sees judgement as merely the drawing of conclusions, the temporary isolation of a thing to leap off from it in the form of an experiment. ${ }^{14}$ Thus, while we can argue that our various senses and their coordination can give us a crude psychological or sociological picture of the human, it does not clearly give us a ground for the construction of theories, or judgements, within those fields on their own terms. The development of such theories requires a disentanglement of the ontological and the epistemological, since we cannot know, prior to the result of the experiment (whether cognitive or physical) what the consequences will be.

Idealism suspends the claim that such experiments must necessarily have ontological consequences while at the same time attempting to explain how new methods

${ }^{14}$ See F.W.J. von Schelling, Ideas for a Philosophy of Nature, trans. Errol Harris and Peter Heath (Cambridge: Cambridge University Press, 1988), 10-11. 
are needed to explain how ideas and concepts behave within theories. This leads us to the second-order empiricism mentioned above. The construction of theories, through reflection and judgement but built upon sensory experience, gives us a different kind of experienceable material from which to develop our theories and make our judgements about the broader picture of the world.

\section{Judgement and the Morphology of the Abstract}

If, as we have suggested following Schelling, the investigations of mind require a different methodology and engine of investigation (transcendental idealism) then how do we come to terms with seemingly purely ideal functions (such as judgement) when they are made upon a supposedly external world? This is even further complicated if the capacity to judge something to be this or that is ungrounded, unstable, and yet simultaneously a distant relative of more original natural processes. That is, the ideal isolation of an object from its environment seems to remove it twice over. In seeing it as an isolated object one must suspend, or at least limit, questions regarding its origin and effects. Following this, the object is judging according to our (the thinking agent's) criteria thereby dislocating the object from real space altogether.

To get a foothold in experience, to find a rung for our hand to grasp, so to speak, must we formally excise ourselves from experience, and is this excision itself only an excision formally? This would seem merely to exacerbate the problem noted above regarding the failure 
of self-access. If nothing can be an object to itself, then jumping 'further' out of the relation via the use of formalisms, such as logic, does not immediately appear as helpful. However, formalisms can be effective when one takes into account exactly what the failure of self-access entails, what logic means for the idealist tradition, and how this feeds into a particular notion of judgement which could be taken to be material or perhaps embodied (following our above appeal to an extended naturalism).

The strange attitude towards formalism is particularly evident in the work of Bradley.

Bradley, and the idealist attitude towards formalism generally (whether logic or of the mental faculties) was that it froze and shattered the world only to reconstruct it in an incomplete manner. Kant's purported unity of the mind was too problematic an assertion for T.H. Green, Bradley, and even earlier in the case of Schelling. A well-known quote by Bradley from his massive text on logic is illustrative here:

Unless thought stands for something beyond mere intelligence, if 'thinking' is not used with some strange implication that never was part of the meaning of the word, a lingering scruple still forbids us to believe, that reality can ever be purely rational. It may come from a failure in my metaphysics, or a weakness of the flesh which continues to blind me, but the notion that existence could be the same as understanding strikes as cold and ghost-like as the dreariest materialism. That the glory of this world is in the end appearance leaves the world more glorious, if we feel it is a show of some fuller splendour; but the sensuous curtain is a deception and a cheat, if it hides some colourless movement of atoms, some 
spectral woof of impalpable abstractions, or unearthly ballet of bloodless categories. ${ }^{15}$

This is not to say that a methodological or formal self-excision from the world does not have its uses, so long as it is not taken for more than it is (again following Bosanquet's reality principle). Similarly, Bradley states that it is nonsensical to claim that appearances can be conjured away, or that they have no use. Appearance is a part of reality for Bradley; the question is how to engage with appearance in a way that does not collapse the limits of our knowing with the limits of reality, either in a way that artificially halts our knowing, or that mystifies the world in such a way that we can be content with its unknowability.

For Bradley, feeling as immediate experience, while insufficient in the forming of an argument or a judgement, carries with it a volition which codes the thoughts and the appearances, and the thoughts on the appearances that follow an experience that is felt. In essence, the immediacy of feeling cannot be removed from our experience but the error lies in thinking that this notion of immediate experience can be expanded to all of reality as such. To do so would either fall into solipsism (all reality is $m y$ reality) or it would equate thinking with being in a manner such that the difference between the two, between thought and the thing it thinks, would disappear, thereby eliminating both.

15 F.H. Bradley, Principles of Logic (Oxford University Press, 1922), 533. 
This somewhat abstract formulation of feeling and its limited immediacy relates to Schelling's theory of judgement. As Marcela Garcia has brilliantly examined, Schelling's judgement cuts or separates terms to re-unify them into a higher form. But the lower forms are not replaced, nor are they destroyed; they become the geological layers of the ground which sustains the capacity of judgement higher up the ladder. ${ }^{16}$

As Garcia goes on to discuss, judgement, in Schelling's sense, cannot be tied to any notion of immediacy, of vision functioning to give oneself instant knowledge. Judgement involves making explicit the capacity of what has already been represented as ground. ${ }^{17}$ Thus the opposition between naturalism and idealism, or between the original and the derivative, brings with it a further complication regarding how one orders (or judges) the relation of the pre-conceptual and the conceptual. As we have already seen, a methodological difference seems required but this does not tell us how judgements treating judgements should be viewed in relation to naturalism, for instance, nor how judgements treating natural processes should be perceived as either natural processes or judgements.

This requires demonstrating the simultaneous additive and subtractive character of vision, of the experience of an image. Quite straightforwardly, the judging of an image would seem to take place after a series of preceding steps which would occur so quickly as to remain invisible in

\footnotetext{
${ }^{16}$ Marcela Garcia, 'Schelling's Theory of Judgment and the Interpretation of the Copula', Schelling-Studien: Internationale Zeitschrift zur klassichen deutschen Philosophie 3 (2015): 25-49, 27.

17 Ibid., 28.
} 
the present moment of the perception. The steps of this process are themselves only ordered as such following a latent judgement. The forces of physics, biology, and neurochemistry play an entangled role long before we register an image of anything. But by the time we see this image it has already been pre-processed by our conceptual apparatuses (if we take Sellars' myth of the given seriously) ${ }^{18}$ and then we reflect upon the image as if it is free and naked before us, an object just meeting our perception, a perception which is taken generically as 'an experience.'

But these experiences vary in length and seem to seep out of any conceptual definition applied to them. These events, or presents, seem to have a geometry in which the passage of time appears absolutely non-discrete (one could take James' image of the specious present as a saddle as one such example). In other words, I may not take notice of the past seven moments but I fixate on an object before in the eighth moment and it 'seems' to go on forever. Explaining this difference in terms of quantity of time is difficult, given that the measure is taken and experienced by the same 'clock' (my perception). Despite James' pragmatism, his spatialising of experience shares much in common with his idealist forebears and

18 Sellars' myth of the given argues that we cannot rely upon experience as given to us fully formed and then analyzed by our cognitive capacities. Rather, if we accept that we are trained to process evidence, that our conceptual capacities are learned not innate, then we cannot assume that evidence presented before us is not taken apart by that mental training before we have consciously decided to evaluate it. See Wilfrid Sellars, 'Philosophy and the Scientific Image of Man', in Empiricism and the Philosophy of Mind (London: Routledge \& Kegan Paul Ltd., 1963). 
contemporaries. James' and Bosanquet's concerns regarding the shape (or morphology) of intentionality, of the directed thinking toward an experience, appear to productively dovetail. ${ }^{19}$

Given the various shapes of experience, which can be ordered and remade based on how much of the above series of moments we grasp, we can determine what form of the time series can be re-inserted (however imperfectly) into one of its contained parts. Or, in other words, how do we recognise 'the pivotal moment from the sense data' and what changes when we 'play back' the memory chosen to be pivotal? Judgement can be said to be one pass across such an experience that is subsequently offered up for collective judgement, whether such acts express, or at least potentially express, a sense or feeling of the greater landscape.

Thus, long-standing critiques of an over-reliance on vision, or on the weight of reflection in post-Kantian thought, generally assume an immediacy or a clarity which those philosophies have never admitted. One of the most central aspects of idealism, and of post-Kantian idealism especially, was that numerous structural issues impeded not only thought but any processes from being simply self-standing or exhaustive. Quite importantly, however, and what has generally been lost in the neglect of idealism, is the particular way it attempted to map the behaviour of ideas in a spatio-historical sense.

${ }^{19}$ James himself admits this much in his essay 'How Two Minds Can Know One Thing, Journal of Philosophy, Psychology and Scientific Methods 2 (7) (1905): 176-181 
Again, following Garcia, the complexification of vision and its purported immediacy relates directly to the problem of the functional relationship of the normative and the non-normative, and of the pre-conceptual and the conceptual. ${ }^{20}$ Or, in relation to the above discussion, law (as the force of the normative) and non-law (the material which is judged) maps onto the normative and nonnormative whereas the distinction between sense and experience maps (albeit difficulty and imperfectly) onto the pre-conceptual and the conceptual. Going back to the opening pages of this essay, these divisions manifest in the problem of the ontological and the methodological, whether any of these divisions can be said to be made from a neutral position, or whether they are made from one side. In other words, many of those thinkers who follow a particular form of Kantianism (P. F. Strawson, Sellars, McDowell, Brandom) suggest that the cut between the non-normative and the normative is made from the position of the normative. Essentially, according to those on the side of normativity, we must say that the normative decides its own beginning in order for us to make sense of the world through patterns, rules, and laws.

The emergence of patterns, rules, and laws is taken to be groundless from the point of view of the non-normative, and a necessary set of judgements from the position of the normative which, since it has only normative standing,

${ }^{20}$ Karen Barad's consistent claim that reflection is a relatively straightforward process that over-simplifies reality is a prime example of this. See her Meeting the Universe Halfway: Quantum Physics and the Entanglement of Matter and Meaning (Durham: Duke University Press, 2007). 
becomes auto-generating. In the case of law, while precedence can be taken into account for a law's effectiveness and modification, it does not justify the law's existence. Only authority, itself not strictly legal in the same sense, does this.

But can this game be played so that the normative always avoids non-normative grounds, or can the normative always be tainted by what it wishes to keep outside?

\section{Conclusion or Vision of Law}

While the normative (at times) appears to be made of the non-normative, so, too does sense appear to fully compose the bedrock of experience. The wrinkle is that we do not encounter this relationship in this way; rather, we have to reverse engineer it. In other words, we do not sense sense as sense but we instead have an experience which allows us to dig into the functions of sense. The difficulty, again to state the obvious, is to what degree can we strip experience of experience to experience sense without either deluding ourselves to think we can 'get out of our own heads' or to think we can never think the nonconceptual or pre-conceptual?

It is perhaps not surprising that Kant, partially in order to avoid such headaches, wished to hold on to a portrait of reason that operated as its own judge and jury, to argue that only reason can stand as arbiter over reason. As has been frequently noted, Kant was fond of the legal claim, of adding philosophical charge to the question of 
justification: Quid Juris? (by what right, or, what is lawful) is central to Kant's philosophical project. ${ }^{21}$

One pertinent question would be the difference between the general structure of judgement as merely the capacity to draw conclusions, and the judgment of the court, of the relation between collective normativity and the precedent which functions as the material, as the background, of the judgment. In order to take judgement into question as a form of data, it is required to view the capacities of reason, of which judgment is merely one, as a collection of senses comprising a vision of the mind. How would one construct a vision of the law in this manner?

If the force of law is taken to be not merely autochthonic, or self-grounding, nor as merely ontological, guaranteed by an in-built democratic principle (such as Schelling's Weltgesetz or Bosanquet's reality principle taken as totalising), then law becomes a seeing of ideas as rules and the construction of rules for ideas. The ramifications for such a project may be difficult to ascertain at this brief glance but idealism remains the proper tool for a philosophy of law that takes the inscription of normativity into legality as an experiment on the flexibility of a concept as a regulator of space (both ideal and real).

Taking the force of law as a type of vision emphasises its force as one of collective apparatuses more than a groundless violence. Furthermore, and again nodding to objective idealism and its Naturphilosophical roots, such

${ }^{21}$ Immanuel Kant, The Critique of Pure Reason, translated and edited by Paul Guyer and Allen Wood (Cambridge University Press, 1998), 219, (A84/B116). 
force is only possible according to rules that precede its own rules: the patterns of nature. Thus, while representation and thus appearance seem necessary components of reality, the form of judgement necessary for thought is far from having been effectively, and collectively, articulated.

\section{References}

Barad, Karen. Meeting the Universe Halfway: Quantum Physics and the Entanglement of Matter and Meaning. Durham: Duke University Press, 2007.

Berkeley, George. An Essay Towards a New Theory of Vision. London: Classical Reprint, 1709.

Berkeley, George. Principles of Human Knowledge. Oxford: Oxford University Press, 1710/1996.

Bradley, F.H. Appearance and Reality: A Metaphysical Essay. London: George Allen, 1893.

Bradley, F.H. Principles of Logic. Oxford: Oxford University Press, 1922.

Garcia, Marcela. 'Schelling's Theory of Judgment and the Interpretation of the Copula'. In Schelling-Studien: Internationale Zeitschrift zur klassichen deutschen Philosophie Philosophie 3 (2015): 25-49.

Hamilton Grant, Iain. 'Everything. In The Monist 98, no. 3 (2015): 156-167.

Hamilton Grant, Iain. 'The Law of Insuperable Environment: What is Exhibited in the Exhibition of the Process of Nature?'. In Analecta Hermenutica 5 (2013).

Hamilton Grant, Iain. Philosophies of Nature after Schelling. London: Continuum International Publishing Group, 2006. James, William. 'How Two Minds Can Know One Thing. In Journal of Philosophy, Psychology and Scientific Methods 2, no. 7 (1905): 176-181

Kant, Immanuel. Critique of Pure Reason. Translated by Norman Kemp Smith. New York: St Martin’s Press, 1929. 
Kant, Immanuel. The Critique of Pure Reason. Translated and edited by Paul Guyer and Allen Wood. Cambridge University Press, 1998.

Schelling, F.W.J. von. Darstellung der reinrationalen Philosophie (SW II/1, 492)

Schelling, F.W.J. von. Ideas for a Philosophy of Nature. Translated by Errol Harris and Peter Heath. Cambridge: Cambridge University Press, 1988.

Sellars, Wilfrid. 'Philosophy and the Scientific Image of Man'. In Empiricism and the Philosophy of Mind. London: Routledge \& Kegan Paul Ltd, 1963. 